\title{
The Factors that Influence Adoption of ICTs by Recent Refugee Immigrants to New Zealand
}

\author{
Eltahir F. Kabbar and Barbara J. Crump \\ Department of Information Systems, City, Massey University, \\ Wellington, New Zealand
}

\author{
E.F.Kabbar@Massey.ac.nz B.J.Crump@Massey.ac.nz
}

\begin{abstract}
Research indicates that to effectively participate in today's global digital information age, Information and Communication Technologies (ICTs) familiarity is essential for individuals and communities. There is concern, especially amongst developed nations that advances in, and the rapid growth of, ICTs has the possibility of creating a new form of inequality among individuals. The New Zealand government recognises the potential for some sections of society to be alienated from the new digital environment and has made a commitment to creating an inclusive society where all individuals have the opportunity to access and effectively use ICTs. This paper presents results from a qualitative study with the goal of identifying the factors that influence ICTs' adoption by recently arrived immigrants from developing countries, the majority of whom are refugees, and who had settled in Wellington, New Zealand's capital city.
\end{abstract}

Keywords: ICTs adoption, digital divide, refugees, immigrants, social inclusion, Rogers' DOI.

\section{Introduction}

Over the past decade many governments have conducted national surveys to monitor who is, and who is not, participating in this digital world. In 2002 the US Department of Commerce reported that despite over half the American population being online, noticeable divides existed based on education, income, age and race (NTIA, 2002). European and Australian data provide a similar picture of access and social inequalities (Burrows, Loader, Pleace, Nettleton, \& Muncer, 2000; Hellwig \& Lloyd, 2000).

New Zealand reports show that despite various initiatives to bridge the divide, individuals on low incomes, sole parents, older people, those with no or low qualifications or poor literacy, the unemployed, and people with disabilities are at risk of exclusion from the digital age (Cullen, 2001; Smart Newtown Project, 2003). Across these disadvantaged groups new immigrants are often over-represented and frequently live in "informational cities" that "deepen existing patterns of socio-spatial segregation" (Castells, 1999, p. 27). Immigrants arriving in New Zealand find a

Material published as part of this publication, either on-line or in print, is copyrighted by the Informing Science Institute. Permission to make digital or paper copy of part or all of these works for personal or classroom use is granted without fee provided that the copies are not made or distributed for profit or commercial advantage AND that copies 1) bear this notice in full and 2) give the full citation on the first page. It is permissible to abstract these works so long as credit is given. To copy in all other cases or to republish or to post on a server or to redistribute to lists requires specific permission and payment of a fee. Contact Publisher@InformingScience.org to request redistribution permission. multicultural society, with nearly 20 percent of the population originating from more than 140 countries (Statistics New Zealand, 2002). Immigrants face unique and challenging situations in their early settlement years (Gubbay \& Cogill, 1988) and for those from countries where ICTs are not ubiquitous, an additional challenge will be adjusting to life in New Zealand where computers 
are commonplace. The New Zealand government has committed to creating a digital future for all New Zealanders, using the power of ICTs and states that "it's about people and their ability to connect to the things that matter to them." (see www.digitalstrategy.govt.nz ).

\section{New Zealand's Digital Strategy}

The New Zealand government's vision for its Digital Strategy, launched in May 2005, aims to position New Zealand as a world leader in using ICTs so that economic, environmental, social and cultural goals are realised (New Zealand Government, 2005). There is an emphasis not only on business and government but also on people. To realise this vision, the government is providing a contestable Community Partnership Fund of $\$ 20.7$ million to partly fund initiatives that will improve people's capability and skills to use ICT and develop digital content (Community Net, 2005), thus ensuring "a digital future for all New Zealanders whether they're at home, school, work or in the community " (Community Net, 2005, p. 1). The strategy has a cultural and social focus on communities that recognises the need to provide an integrated and cohesive framework that encourages the uptake and effective use of ICTs by all citizens.

\section{Immigrants and ICTs}

A literature search found limited studies that focused on immigrants' use of ICTs and none that investigated the factors that influenced recent immigrants, particularly those from developing countries, in their adoption or non-adoption of ICTs.

Campbell's (2002) New Zealand study investigated the socio-cultural impacts of ICTs on immigrants, the majority of whom were "relatively well-off" (p. 11). The study found that most of the immigrants who participated in the study reported using ICTs frequently for both word processing and accessing the Internet. This clearly indicates that the group of immigrants who responded was among the adopters of ICTs and had a high access level to the technologies.

Another study by Chonia (2002) highlighted some of the problems facing many immigrants when they adjust to life in Switzerland where ICTs are part of daily living. Poor literacy, lack of local information, inadequate language skills as well as immigrants' cultural background were identified as the main barriers that prevent immigrants from adopting ICTs.

Because ICTs play an increasingly central role in the workplace and society in general, knowledge and experience with ICTs are becoming essential, particularly from a social inclusion perspective. The importance is emphasised by Fleisher (cited in Mitchell, 2002) when he says

Not knowing how to and being unable to access technologies designed to communicate digital information, such as the Internet, may, in the future, be equivalent to not knowing how to read and write today (p. 2).

Identifying the factors that influence adoption or non adoption of ICTs is therefore an important first step to understanding what is required to promote ICTs adoption among this group. This paper presents results of a study of refugee immigrants living in Wellington, New Zealand's capital city, and their adoption or non-adoption of ICTs. The focus of this study was on the adoption and non-adoption of personal computers and the Internet, either at home or work. Participants were asked about their use of other communications devices, for example cell phones and personal digital assistants. In the context of this paper the term immigrants and refugees are used interchangeably to refer to people who came to live in New Zealand regardless of their immigration status. This reflects the status of the majority of the volunteer participants who participated in this study and who were recruited through the Refugee and Migrant Services (RMS) Wellington branch. We begin by describing the research design, which is followed by presenting and discuss- 
ing the results and conclude with discussion of the limitations of the study and the implications for practitioners who are interesting in promoting ICTs adoption among disadvantaged groups.

\section{Research Design}

\section{Aim}

This qualitative study investigated the factors influencing the adoption and non adoption of ICTs by recently-arrived immigrants; those who live in New Zealand and who first arrived to live here five years ago or less (New Zealand Immigration Service, 2003). The study objectives were to:

1. understand recently-arrived immigrants' perceptions of ICTs

2. examine the factors that influence immigrants' adoption and non adoption of ICTs

3. understand the process followed by recently-arrived immigrants when adopting ICTs.

\section{Method}

Semi-structured interviews were used to collect data from recent immigrants. Because the conventional one-off, professional interview is considered unsuitable for vulnerable social groups (Russell, 1999) it was decided to have two rounds of interviews. The first interview, which took about 45 minutes, provided the opportunity for the study's purpose to be explained and questions to be answered. Importantly, it enabled the researcher to form a relationship with the refugee participants. A relationship of trust was important, as many of the participants had suffered traumatic experiences that may have caused them to approach the interview with feelings of trepidation and reluctance to participate openly if there had been just the one-off interview.

Data relating to the different cultures, country infrastructures and background of the participants' ethnic groups were also collected from secondary sources such as the New Zealand Census statistics and the Refugee and Migrant Services' (RMS) publications. The interviews, often facilitated by ethnic community leaders, were audio-taped and transcribed by the researcher prior to analysis.

\section{Sample}

The target population of this research project was recently-arrived immigrants (mostly refugees) living in the greater Wellington area. The manager of the RMS, Wellington branch, assisted with recruitment of participants, which resulted in a self-selected, volunteer sample of 32 recent immigrants living in 15 households. They were between the ages of 12 and 65 years and came from developing countries that included Africa, the Middle East, Central Asia and South East Asia. It is recognised that there are country differences within these broad regional categories but for the purpose of this study, the Statistics New Zealand categories were adopted. Some of the interviewees had experienced war-time trauma, some came from repressive regimes and they had varying English-ability levels that ranged from limited knowledge to fluent English. Table 1 reports the number of household participants (32) and the gender composition of the sample from each region (17 female and 15 male). Most of participants were from Africa (12), with the next largest cohort of nine from countries in the Middle East. 
Table 1: Numbers and age of participants from the four regions

\begin{tabular}{lccr} 
REGION OF ORIGIN & NUMBER OF HOUSEHOLDS & \multicolumn{2}{c}{ GENDER } \\
Africa & 6 & 7 & 5 \\
Middle-East & 4 & 5 & 4 \\
Central Asia & 3 & 3 & 4 \\
South East Asia & 2 & 2 & 2
\end{tabular}

The sample is considered to be reasonably representative of immigrants from developing countries living in the Wellington region, as over 25 percent of the total immigrant population in that region are from these countries (Statistics New Zealand, 2002).

\section{Analysis}

Rogers' Theory of Diffusion of Innovation (DOI) (Rogers, 1995) contributed to the theoretical framework for this study and informed analysis of responses to the semi-structured interview questions. The DOI theory is widely used to help understand how new innovations are diffused and adopted by individuals.

Rogers (1995) developed a five stage linear model (see Figure 1) to identify and explain the different stages individuals follow, over a period of time, before they decide whether to adopt or reject an innovation. These stages are Knowledge, Persuasion, Decision, Implementation and Confirmation and are described below.

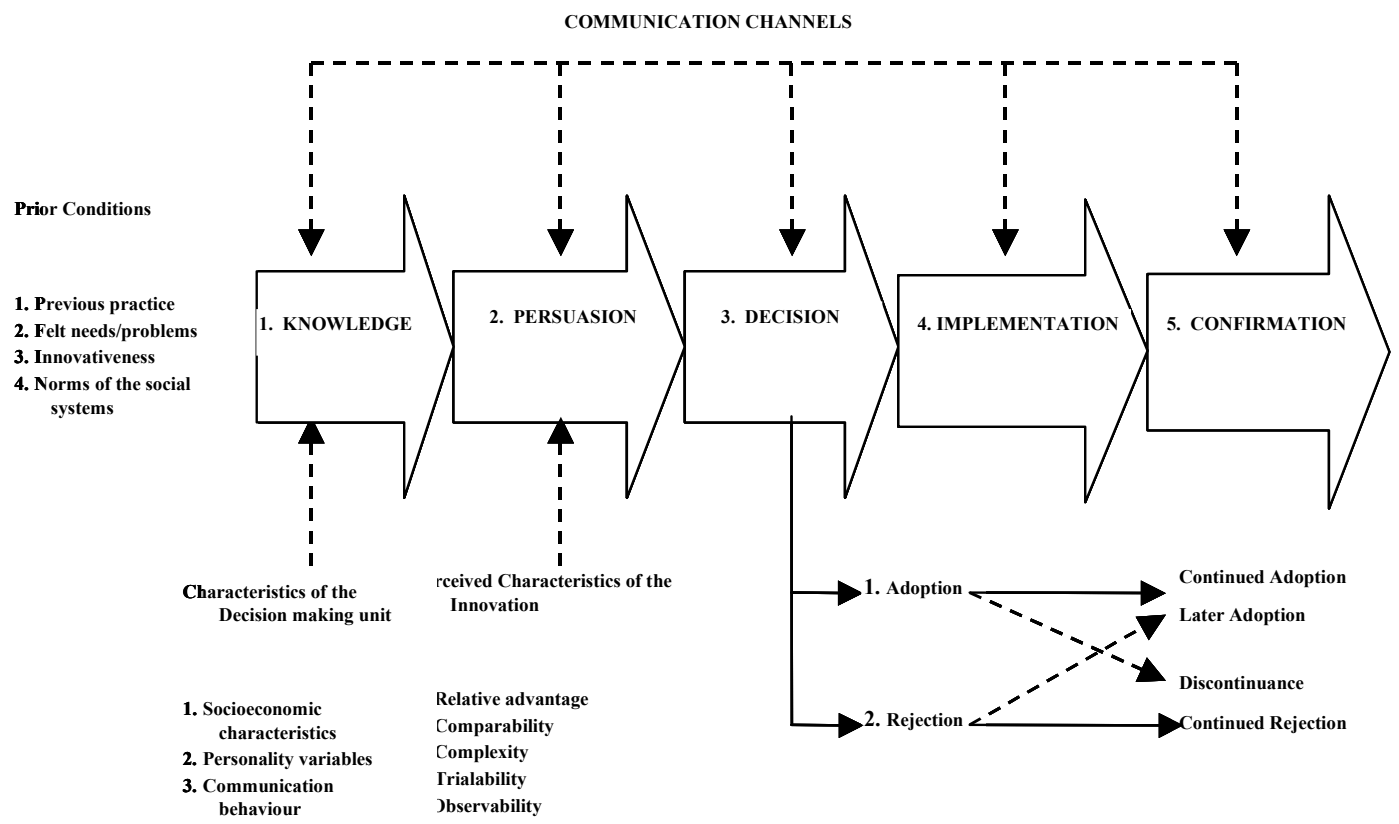

Figure 1. A model of five stages in the innovation-decision process. Soruce: Rogers, 1995, p. 163. 
Knowledge: at this stage an individual (or a group) comes to know about the existence of an innovation, its potential usage and functionality via communication channels. An individual is motivated to actively seek knowledge about an innovation. This involves exploring the advantages and disadvantages of the innovation and results in reducing the uncertainty associated with innovations.

Persuasion: at this stage an individual (or a group) formulates their own idea about the innovation. Potential adopters create an either positive or negative attitude or image about the innovation. At this stage the perceived characteristics of innovation described earlier (Simplicity, Trialability, Observability, Relative advantage and Compatibility) will greatly shape the individual's attitude towards the innovation.

Decision: at this stage an individual (or a group) decides whether to adopt (make full use of the innovation) or reject (not to adopt the innovation) based on the knowledge gained and the attitude or image formed about the innovation by potential adopters. The decision to adopt or reject an innovation can be reversed at a later stage. Individuals who decide to adopt an innovation can both continue the adoption and proceed to the implementation stage or they may decide to reject an innovation that they have adopted at an earlier stage (known as 'Discontinuance'). On the other hand individuals who decide to reject an innovation at an earlier stage may either continue to reject the innovation or decide to adopt it at a later stage creating what is known as 'Later Adopter'.

Implementation: once individuals decide to adopt an innovation the implementation stage begins. At this stage individuals actually start using the new innovation. An individual's usage of an innovation can lead to some changes or modifications to the original innovation (Reinvention) during the adoption process.

Confirmation: at this stage an individual (or a group) evaluates the use of an innovation, looking for evidence to support the continued use of the innovation. If the evaluation is negative, the individual reverses the decision to adopt.

Once data collection was completed, a qualitative software program (QSR N6) was used to help analyse, manage and search the data. The verbatim transcripts were read and re-read while looking for patterns and themes. During the readings the interview data was subjected to three separate rounds of coding (Strauss, 1987). The surfaced themes became the "units of meanings" (Miles \& Huberman, 1984) - such as ICTs Access. The units of meanings were then grouped into different categories and organised in tree nodes (QSR N6 term for text units organised hierarchically to represent categories and subcategories). For example, the ICTs Access unit was further organized into subcategories of Computer Access at Home, Educational Background, Gender and Age, etc.

\section{Results and Discussion}

The results show that among the 32 individual participants from the 15 households, 13 stated that they were non-adopters and 19 identified themselves as adopters. The majority of the nonadopters were older immigrants, especially women, five of whom had no formal education. Discussion of the major themes is presented under the following headings of Immigrants' Perceptions of ICTs, Factors Influencing Adoption of ICTs, Understanding the Adoption Process, Barriers to Adoption, Online Content and Learning Mode.

\section{Immigrants' Perceptions of ICTs}

Overall, the interview results showed that the majority of recent immigrants, be they adopters or non-adopters, perceived ICTs as useful, relevant and important for them thus providing the impe- 
tus for adoption. This finding confirms Rhee and Kim's (2004) contention that a positive attitude towards technology is important in influencing adoption. However, many of the participants who had recently adopted computers used them in a very limited capacity, mostly as a communication tool to contact friends and family members overseas through emails and web based communication tools such as MSN messenger and Yahoo messenger. Hence there is a need to raise the awareness of this group of the further potential of ICTs to benefit them through such activities as learning English, Internet banking, applying for jobs, dealing with, and being informed of, local and central government services - content that is increasingly offered online, and children's educational sites.

Most of the non-adopters viewed ICTs positively and they expressed their desire to learn how to use computers and the Internet if they had the opportunity to do so. However they felt that their lack of sufficient English language in addition to lack of knowledge about computers and the skills required to operate them were the main barriers. One of the non-adopters, a 45-year-old female, didn't express such a desire. She perceived ICTs as a tool for the younger generation and considered it was too late for her to participate in ICTs because of her age, saying: "It is not my time.... I am too old for it".

A small number of the recent immigrants perceived computers and the Internet to be difficult to use and struggled to learn the skills required to participate in ICTs. For example a 56-year-old female stated that: "it is too hard. I find it hard to remember how to operate them [computers]". Despite the difficulties associated with learning, none of the participants perceived the benefits of ICTs negatively. All but one female non-adopter indicated that they would want to learn about computing in the future.

Some parents had safety concerns regarding what their children might access online. They thought that some of the Internet content conflicted with their cultural, religious and social norms and they believed they needed to closely monitor their children's online activities. For example a 48-year-old female stated that "... at the same time it [the Internet] is very bad for children. You don't know what they can access or do on the Internet. Not everything is useful in the Internet". Despite these concerns, the majority of parents perceived ICTs positively and placed a high priority on having access to ICTs at home, mainly for their children's educational needs.

\section{Factors Influencing Adoption of ICTs}

\section{Family and friends}

Many of the interviewees cited friends and family members as the biggest influence in their choosing to adopt ICTs. They stated that they first knew about computers from friends and family and that they observed their friends using ICTs for a period of time before they decided to adopt. This observation period varied from a few weeks to several months. The majority of the participants indicated that they were persuaded by friends and family and peers from their wider community to try and use ICTs. For example a 26-year-old male participant stated that: "I just watched my friends, it was informal. It took me a long time; maybe six to eight months since I've watched my friends using computers to really start using computers".

\section{The wider ethnic community}

The second major influencing factor in recent immigrants' decisions to adopt ICTs was members of their larger community. Recent immigrants indicated that they followed the lead of their trusted ethnic community peers in the use of ICTs and ownership of personal computers. The majority of adopters stated that they participated in ICTs because "everyone" in their community was doing so and they wanted to emulate this practice. For example a 17-year-old Somali female 
participant, when asked about her motivation to learn about computers, stated, "I think it is because everybody is using it so you know you just want to copy them. Another 44-year-old female participant, when answering the interview question "What made you decide to use computers and the Internet?" said: "It is a new technology. Everybody is using it, everyone in the community talks about it so you do not want to be sitting without knowing anything when they talk about it."

\section{Relative advantage}

Recent immigrants perceived ICTs as an 'innovation' that gave them a relative advantage (such as cost savings when communicating with friends and family members overseas). As well, recent immigrants easily observed other, more established immigrants using ICTs in their homes. A 24year-old male participant illustrated this point, saying: "I need something to use to communicate with my family back home and using the phone was expensive. I found that the email and MSN Messenger was a cheaper alternative". These two innovation characteristics of relative advantage and observability have been found to be influential in ICT adoption. Rogers (1995) shows that innovations that possess characteristics such as relative advantage and observability are likely to persuade potential adopters and hence increase the innovation's rates of adoption and this has been confirmed in this study.

\section{Understanding the Adoption Process}

The above discussion identifies factors influencing ICTs adoption, thus contributing to an understanding of how the participants of this study adopted ICTs. Many of the adopters followed the five stages of Rogers' Innovation-Decision Process model. The stages are: Knowledge, Persuasion, Decision, Implementation and Confirmation.

While Rogers' five stages are helpful in understanding the adoption process, the results of this study suggest that Knowledge and Persuasion occurred over varying time spans (depending on the individual). The time spans were noticeably shorter for younger, relatively well-educated and male immigrants. Furthermore most of the participants (both adopters and non-adopters were favourably disposed to learning about computers thereby providing strong motivation to adopt ICTs. They trusted in, and relied on, their immediate friends and family networks for support, advice and information (especially in the initial settlement period in a new country). Within this smallish group the ethnic community leaders were the "opinion leaders" (Rogers, 1995) and once they were seen to use ICTs others wanted to follow.

None of the participants who identified themselves as ICTs adopters indicated that they had discontinued or rejected ICTs after an initial adoption. However a few participants stated that the number of hours that they spent using computers and the Internet had reduced. This was attributed to different reasons including a decline in the level of their ICTs enthusiasm and interest, lack of usage opportunities and lack of time.

\section{Barriers to Adoption}

The results revealed that physical access to ICTs and network connectivity did not appear a major adoption barrier for this group. All those who identified themselves as adopters (over half the interviewees) indicated that they had access to computers and the Internet at home. This was a surprising finding because many within this group of refugees were low-waged and some unemployed, thus suggesting that they placed a high priority on home access by owning their own computer. One of the reasons given for placing such a high priority on home access was that recent immigrants, especially females, did not feel comfortable accessing computers and the Internet outside the home. This could be attributed to the 'newness' of their new society together with cultural reasons where women are not allowed to access computers at public places for long peri- 
ods of time. Another reason for the high computer ownership could be attributed to the steady decline in the prices of personal computers, which makes ownership more affordable, even for a mostly low-waged group.

Unlike the physical access factor, the 'skill access' and the 'usage access' factors identified by van Dijk (2003) appeared to be significant barriers to recent immigrants' adoption of ICTs. The majority of the participants indicated that they lacked computing experience (most of them stated that they started using ICTs after arriving in New Zealand). They had no formal ICTs training and it had not been part of their basic educational background. Most immigrants indicated that they were totally dependent on their friends and family to gain the skills required for using technology. In many cases those friends and family members were new to ICTs and possessed elementary skills only.

The results showed that the majority of recent immigrants, especially females, older immigrants and those with no, or very limited, educational background, lacked the opportunities to use ICTs in a job or school-related activities. Most of the participants said that their ICTs usage was limited to communicating with friends and family members overseas and accessing news from back home.

\section{Online Content}

Immigrants of all ages who participated in this study, regardless of education and ICTs experience, expressed their desire to see more online content, especially of New Zealand government sites that provide useful information necessary in their early re-settlement months. Examples of these sites relate to the departments and ministries of the Inland Revenue, Work and Income, Education and Immigration. For instance, a 32-year-old female participant indicated that: "there are not much New Zealand based sites, I think, in our language. There are very few sites that we can access in our mother tongue". It is appreciated that immigrants are living in a country where English is the dominant language but information in the immigrants' native languages will aid the transition to their new society. Currently those who are not fluent in English rely on an intermediary for interpretation. Translations of parts of some United States government web sites are available in alternative languages, for example, for the Hispanic community and this has been found useful (West, 2001).

\section{Learning Mode}

Despite some new immigrants attending free community computing classes to learn about ICTs, the preferred method cited by participants of this study was the one-on-one, face-to-face method. Sharing and exchanging information about ICTs was predominantly done through word of mouth and in a face-to-face setting (mostly in their own or friend's home) with the co-ethnic community members being the primary source of information.

\section{Conclusion}

The purpose of this qualitative study, using an analytical framework of Rogers' Diffusion of Innovation Theory (DOI), was to better understand recent immigrants' perceptions of ICTs, what causes them to adopt or not adopt ICTs, and the factors that influence such action. Some researchers of complex organizational technology and intra-organisational information systems have criticized the deficiencies of the DOI in explaining adoption behaviour (Brancheau \& Wetherbe, 1990; Fichman, 1992) but the DOI theory has been found useful for this refugee immigrant study. The theory informed the schedule of interview questions and provided an understanding of the adoption of ICTs; particularly how the refugee participants knew about ICTs, why they were persuaded (or not) and what affected their decision to adopt (or not). 
Overall, the results show that while the majority of the participants lacked computing experience, they had positive perceptions about ICTs, its usefulness and importance. Young, male participants with a relatively higher educational background were more likely to be adopters. In contrast, older female participants with little or no education were less likely to participate in ICTs. Furthermore, the results show that immigrants are greatly influenced by their peers, immigrants' community leaders and the wider immigrants' community when deciding to adopt or reject ICTs.

This study has several limitations. Despite being an acceptable sample size (32) for a qualitative study, the study focused on recent immigrants in Wellington who arrived as refugees from developing countries of two main geographical regions. The results may therefore not be representative of immigrants coming from other areas of the world or, living in other locations within New Zealand. The potential for interviewer bias was offset by holding two rounds of interviews and the interview transcripts returned to the participants for validation. Triangulation was achieved on data (different sources), time and space (Denzin, 1988).

The findings of this study have important implications for realising the vision of New Zealand's Digital Strategy to create an inclusive society where all members, including recent immigrants, are able to access and use ICTs and hence be able to fully participate in the Information society. The consequences to society resulting from inequalities in the skills in, and usage of, ICTs have been discussed by van Dijk and Hacker (2003). These researchers note that a fundamental task of society is to prevent these inequalities from cementing into structural inequalities where they "solidify" and become barriers to advancement in society." (p. 324).

\section{References}

Brancheau, J. C., \& Wetherbe, J. C. (1990). The adoption of spreadsheet software: testing innovation diffusion theory in the context of end-user computing. Information Systems Research, 1(2), 115-143.

Burrows, R., Loader, B., Pleace, N., Nettleton, S., \& Muncer, S. (2000). Virtual community care? Social policy and the emergence of computer mediated social support. Information, Communication and Society, 3(1), 95-121.

Campbell, N. (2002). Socio-cultural impacts of information and communication technologies on immigrants in New Zealand. Hamilton: New Zealand: Dept. of Management Communication, University of Waikato.

Castells, M. (1999). The information city is a dual city: Can it be reversed? In D. Schön, B. Sanyal, \& W. Mitchell (Eds.), High technology and low-income communities: Prospects for the positive use of advanced information technology (pp. 25-43). Cambridge, MA and London: MIT Press.

Chonia, G. (2002). Bridging the digital divide in a digital society. Switzerland: University of Zurich, Centre for Computing.

Community Net (2005). The Community Partnership Fund. Retrieved on November 11, 2005 from http://www.digitalstrategy.govt.nz/templates/Page_18.aspx

Cullen, R. (2001). Addressing the digital divide. Online Information Review, 25(5), 311-320.

Denzin, N. K. (1988). Triangulation. In J. P. Keeves (Ed.), Educational research methodology and measurement: An international handbook. Oxford, United Kingdom: Pergamon Press.

Fichman, R. G. (1992). Information technology diffusion: A review of empirical research. Proceedings of the Thirteenth International Conference on Information Systems (ICIS), 195-206.

Gubbay, D., \& Cogill, S. (1988). An asset to the country: The effective use of educational resources to assist the successful settlement of immigrants and refugees. Wellington, New Zealand: Ministry of Education. 
Hellwig, O., \& Lloyd, R. (2000). Sociodemographic barriers to utilisation and participation in telecommunications services and their regional distribution: A quantitative analysis. Retrieved December 12, 2004 from http://www.natsem.canberra.edu.au/pubs/netaccess-barriers.html

Miles, M. B., \& Huberman, A. M. (1984). Qualitative data analysis: A new sourcebook of methods. Beverly Hills, CA: Sage.

Mitchell, M. (2002). Exploring the future of the digital divide through ethnographic futures research. First Monday, 7(11). Retrieved February 15, 2004, from http://www.firstmonday.org/issues/issue7_11/mitchell/

New Zealand Government. (2005). The digital strategy: A summary. Retrieved July 29, 2005, from http://www.digitalstrategy.govt.nz/upload/Documents/MED11706_Summary.pdf

New Zealand Immigration Service. (2003). Migrants in New Zealand: An analysis of 2001 census data. Wellington, New Zealand: Department of Labour.

NTIA. (2002). A nation online: How Americans are expanding their use of the Internet. Retrieved September 12, 2004 from http://www.ntia.doc.gov/ntiahome/dn/nation_online.pdf

Rhee, K., \& Kim, W. (2004). The adoption and use of the Internet in South Korea. Journal of ComputerMediated Communication (JCMC), 9(4). Retrieved December 10, 2004, from http://jemc.indiana.edu/vol9/issue4/rhee.html

Rogers, E. M. (1995). Diffusion of innovations (4th Ed.). NY: The Free Press.

Russell, C. (1999). Interviewing vulnerable old people: Ethical and methodological implications of imagining our subjects. Journal of Aging Studies, 13(4), 403-17.

Smart Newtown Project (2003). Submission by Wellington City Council, Fujitsu NZ Ltd, Wellington Regional 2020 Communications trust, Positively Wellington Business and Smart Newtown, Wellington: Positively Wellington Business.

Statistics New Zealand. (2002). 2001 Census of population and dwellings: Ethnic groups. Wellington: Statistics New Zealand.

Strauss, A. L. (1987). Qualitative analysis for social scientists. Cambridge, England: Cambridge University Press.

van Dijk, J, \& Hacker, K. (2003). The digital divide as a complex and dynamic phenomenon. The Information Society, 19(4), 315-326.

West, D. M. (2001). Urban e-government: An assessment of city government. Retrieved on April 18, 2005, from http://www.brown.edu/Departments/Taubman_Center/polreports/egovt01city.html 


\section{Biographies}

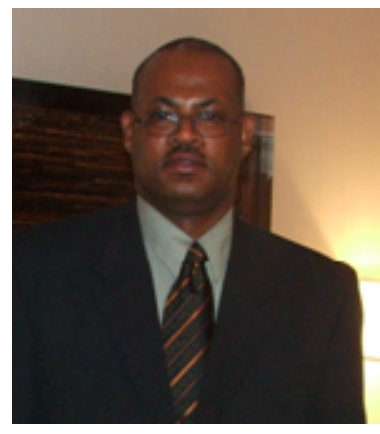

Mr. Eltahir Kabbar teaches information systems at Massey University, Wellington, New Zealand. Over the last two years he has been working on a Masters research project looking at ICTs adoption by ethnic minorities in New Zealand. The Masters degree was awarded in 2005. Another area of research interest is the realization of Egovernment and its impacts on developing countries.

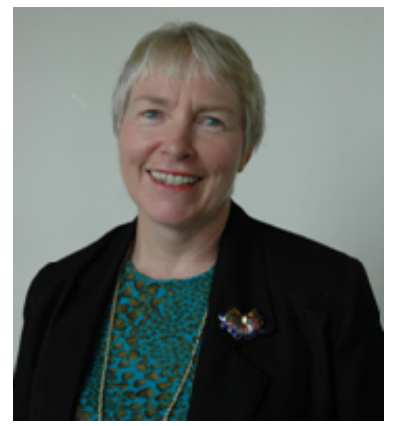

Over the past six years Dr Barbara Crump has been involved in evaluating the Smart Newtown Project, a community computing digital divide initiative in Wellington. She continued this interest when she was appointed Visiting Scholar at the University of Malaya, Kuala Lumpur in 2004. Another area of research interest is the low participation of women in tertiary computing programmes and their involvement in the IT industry. This has led to a commissioned national study of women in the IT workforce that was replicated in Selangor State and Kuala Federal Territory, Malaysia. 